\title{
IMPACTOS SOCIAIS DA ESCRITA DE CAROLINA MARIA DE JESUS NA ESCOLA
}

Tânia Mara Pedroso Müller Pós-Doutora em Antropologia Social pela Universidade de São Paulo (USP) Professora Associada da Universidade Federal Fluminense (UFF) taniamuller@id.uff.br

Sonia Rosa Mestranda em Relações Étnico-Raciais pelo Centro Federal de Educação Tecnológica do Rio de Janeiro (CEFET-RJ) sonrosa@uol.com.br

\section{RESUMO}

Este artigo tem por objetivo analisar os impactos sociais da escrita de Carolina Maria de Jesus, que não faz parte do cânone literário brasileiro. $\mathrm{O}$ texto apresenta uma breve exposição sobre sua vida, uma mulher negra e favelada, abordando suas identidades, e "escrevivências". O texto também reflete sobre a improvável falta de letramento da autora e como seu legado constitui um capítulo importante na história das lutas das classes subalternizadas em busca de reconhecimento. Discute-se o porquê de determinados textos retratarem-na como iletrada, fazendo um aprofundamento na temática sobre o conceito de letramento, a fim de ponderar se cabe à escritora esta condição. Por fim, destaca-se a contribuição de Carolina na literatura negra brasileira e o legado cultural e social do qual ela foi pioneira, ressaltando a importância da inclusão de sua obra no ensino escolar e na formação de professores.

Palavras-chave: cânone, Carolina Maria de Jesus, Literatura negra, letramento, Quarto de despejo.

\section{ABSTRACT}

This article has as objective to analyze the social impacts presents in the novel written by Carolina Maria de Jesus, that isn't part of Brazilian classics. In this paperwork, we'll be presenting a brief exposure about your life, a poor black woman that gained voice. We'll approach her identities, and her life experiences. The unprovable schooling of the author will also be a matter of reflexion, as how her legacy constitutes an important chapter of the lowest class fight searching for recognition. On the other hand, we aim to discuss the many texts opinions on the her as unschooled, and based on that, approach the concept of schooling, in order to consider if the condition of unschooled actually suits the author. We detach, by the end, Carolina's contribution in our brazillian black literature and the cultural and social legacy, in which she was a pioneer, and the importance of her inclusion in elementary school and also in teachers formation.

Keywords: canon, Carolina Maria de Jesus, Black literature, Schooling, Quarto de despejo. 


\section{Introdução}

"Assim como as palavras, as pessoas que as escrevem não podem ser apagadas."

(Carolina Maria de Jesus, 1960)

Na contemporaneidade, ainda é possível verificar os impactos sociais provocados pela escrita de Carolina Maria de Jesus. Em meio ao lixo, a escritora não encontrou apenas detritos, mas descobriu também as palavras nos diferentes livros que garimpava. Era uma mulher que escrevia muito (poesias, dramas, sambas, marchinhas, romances, provérbios, etc.) e colocava o relato de sua vida e sua história em cadernos recolhidos do lixo, o que garantia sua sobrevivência física e mental.

É inegável o legado cultural e social deixado por Carolina Maria de Jesus, dona de uma personalidade transbordante. Tratava-se de uma mulher que rejeitava o papel de artefato de consumo, idealizada pela mídia como a favelada que escreve. Na análise do cenário no qual a autora estava inserida, é visível que não foi aceita plenamente pela elite, pois esta não reconhecia a legitimidade de sua produção. Em seu livro "Quarto de despejo: diário de uma favela" (1960), Carolina conheceu o sucesso, vendeu mais de 10 mil exemplares, contrariando qualquer expectativa, algo jamais visto para uma escritora negra e de sua condição social. Entretanto, a poetisa dos pobres, teve um sério esgotamento ao cair em esquecimento, logo após os grandes festejos provocados pela publicação de seu primeiro livro.

Em 1962, a escritora lançou "Casa de alvenaria: diário de uma ex-favelada", cuja intenção era dar uma resposta à sociedade que não a aceitava e tanto criticava os moradores das favelas paulistanas e a pobreza então existente. Esse trabalho não teve 
boa ascendência e a mídia perdeu o interesse pela autora, uma vez que Carolina ousou subverter os moldes preestabelecidos pela sociedade branca, rica e culta, deixando de ser a escritora favelada, "exótica", que narrava a pobreza, mas também criticava os pobres. Assim, a mídia deu início ao processo de silenciamento e esquecimento da escritora.

A obra de Carolina vai além da escrita e permanece sendo objeto de estudos e reflexões até os dias de hoje. Ressaltamos que a crítica conservadora abrolhou um movimento de recusa à sua autoria e produziu um apagamento velado na tentativa de, aos poucos, excluí-la dos meios e referências literárias.

Apesar de silenciada, depois de estrondoso sucesso e exposição, Carolina se manteve como uma importante representante da literatura brasileira e ainda é reconhecida como original e extraordinária escritora pelo movimento literário, contrariando o que almejava a elite brasileira.

Embora com pouco estudo, Carolina gostava da escrita rebuscada, apresentava preocupação com o vocabulário e construía metáforas consagráveis. Sua escrita era paradoxal, pois dominava a linguagem popular, enquanto reproduzia o preciosismo literário brasileiro. Conhecia bem o lugar de onde falava, pois era testemunha e protagonista da pobreza cotidiana que assolava a cidade paulistana e a todo o país, reproduzindo-a em suas narrativas, o que fez com que José Carlos Meihy (2006, p. 345) justificasse a relevância de sua escrita: "raramente se encontra algo escrito a partir da vivência da pobreza, daqueles que a vivem e dão razão de ser a um estado de coisas que compromete a eficiência dos sistemas políticos e coloca o poder e a ordem social em xeque".

A partir da década de 1990, Carolina Maria de Jesus voltou à cena brasileira, não mais pela mídia, mas pela academia. Cabe considerar que a ascensão da literatura negra e 
da literatura feminina foi fundamental para sua retomada ao cenário literário e acadêmico. Ao optarmos pela análise da sua obra, foi imprescindível abandonar a visão simplista que a situou apenas como escritora necessitada e lançar um olhar mais extenso, para além dos aspectos literários, buscando focar na relevância histórica, antropológica e filosófica de sua obra.

\section{As identidades de Carolina Maria de Jesus}

Nascida 26 anos após a abolição da escravatura, no dia 14 de março de 1914, em Sacramento, cidade rural do Estado de Minas Gerais, Carolina Maria de Jesus teve uma infância pobre e um breve ensino formal. Estudou apenas até a 2ª série, mas se encantou pela escrita e pelos livros. Por isso, anos depois, passou a recolhê-los do lixo sempre que os encontrava.

Com a morte de sua mãe, Carolina foi obrigada a ir para São Paulo, onde trabalhou como doméstica na casa do médico Euryclides de Jesus Zerbini, primeiro cirurgião cardíaco no Brasil. Ele permitia que Carolina usasse sua biblioteca nos dias de folga dela. Após circular por diferentes empregos e jornais onde vendia seus escritos, a autora foi morar na favela do Canindé, e construiu seu barraco com restos de papelão, madeira, sobras de alumínio e telhas de zinco.

Desde pequena, demonstrava inteligência e criticidade, características que a colocava em permanentes conflitos: internos, com seus sofrimentos e buscas de alternativas diárias de sobrevivência; externos, com as negativas de publicação de seus poemas e contos pela imprensa; e com os vizinhos e conhecidos, conforme registrado em 
seus diários. Ousada, Carolina era sempre sobrepujada por sua conduta fora dos padrões socialmente estabelecidos para o seu perfil de negra e pobre.

Por representar uma escrita literária contra-hegemônica, ela se tornou uma escritora basilar e rompeu com paradigmas, ao escrever na favela e da favela; sua escrita literária ficou conhecida mundialmente por sua forma objetiva, dura e realista, pois narrava as condições precárias cotidianas de vida da população subalternizada (SPIVAK, 2010), ou seja, um segmento posto à margem da sociedade.

Carolina Maria de Jesus, mulher, mãe, negra, favelada, apresentada como não letrada (fato passível de discordância), foi definida como a primeira escritora a correlacionar a escrita literária com as questões sociais emergenciais do seu tempo. Defendia seus direitos e fazia seus protestos, descrevendo a realidade da favela em folhas e cadernos que recolhia do lixo. Apesar das conjunturas adversas, cultivou a escrita que se materializava em forma de diários, contos, poemas, entre outros escritos.

Aos 44 anos de idade, Carolina Maria de Jesus foi descoberta pelo jornalista Audálio Dantas, em 1958, quando circulava pela favela para produção de uma reportagem jornalística para o extinto jornal "Folha da Noite". Ao vê-la discutindo com moradores, quis conhecê-la e acabou descobrindo suas dezenas de cadernos-diários. De imediato, viu a riqueza de seus escritos, transformando-a em celebridade instantânea.

Embora fosse parte integrante da favela, Carolina sempre procurou negar essa condição e, por vezes, envolvia-se em conflitos e embates com a própria comunidade, pois tinha padrões rígidos de comportamento, valores morais que destoavam dos modos de vivência local que, por vezes, levavam-na ao isolamento. Isso pode ser justificado pelo seu domínio da leitura e da escrita, conforme ela mesma descreve: "Aqui, todas implicam comigo. Dizem que falo muito bem. [...] Quando fico nervosa não gosto de discutir. 
Prefiro escrever. Todos os dias eu escrevo. Sento no quintal e escrevo"i (JESUS, 2004, p. 19).

Através de suas narrativas, com sua forma direta e forte, a escritora contrariou a estrutura hegemônica, na qual os sujeitos subalternos (SPIVAK, 2010) não encontravam espaço para trabalho, manifestação cultural e enfrentavam todos os tipos de discriminação e racismo. Mesmo que não tenha feito parte do cânone literário, Carolina rompeu os paradigmas vigentes e o silenciamento subalterno de diversos escritores que sempre estiveram à margem da categoria dominante, dando, assim, visibilidade a uma realidade e a sujeitos presentes, até então, apenas como objetos anônimos e coadjuvantes nos discursos literários.

Numa época fortemente marcada por hierarquias de classe e raça (SKIDIMORE, 2012), sua escrita rudimentar e cândida alcançou um expressivo público e um estrondoso sucesso, vendendo um total de 100 mil exemplares do seu livro em mais de 40 países, além de ter sua obra traduzida para mais de 13 idiomas. Ela também ganhou a ira de seus vizinhos, uma vez que suas vidas estavam descritas em seu "Diário".

"Quarto de despejo: diário de uma favelada" (2004) foi publicado em 1960 pela editora Francisco Alves, na cidade de São Paulo e constitui um diário autobiográfico que relata o dia a dia na favela, as mazelas, a fome, a violência, a marginalização, as péssimas condições de higiene, a pobreza, a desigualdade social e a negligência dos políticos com a população subalterna. Trata-se de um livro em que o texto é narrado em primeira pessoa, no qual Carolina desempenha múltiplos papéis: autora, narradora e personagem. É nisso que se encontra sua grande originalidade e, como diria Fernando Pessoa (1942, p. 235), na primeira parte do seu poema "Autopsicografia": "O poeta é um fingidor / Finge tão completamente / Que finge que é dor / A dor que deveras sente". 
Como tão bem ressalta Joel Rufino (2010, p. 33), a importância e o grande destaque provocados pela obra ocorreram por dois motivos:

Para o ocidente liberal e capitalista, seu primeiro livro retratava um sistema cruel e corrupto reforçado durante séculos por ideais colonizadores presentes nas dinâmicas sociais da população. Já para os leitores comunistas, suas histórias representavam perfeitamente as falhas do sistema capitalista no qual o trabalhador é a parte mais oprimida do sistema econômico.

Além de "Quarto de despejo: diário de uma favelada" (1960), obra que pode ser considerada de maior expressividade, a autora também publicou: "Casa de alvenaria" (1961), na qual relata a sua nova rotina e de seus filhos, após deixarem a favela; os romances “Pedaços de fome" (1963) e "Provérbios" (1963), ambos custeados pela própria autora. Anos depois, após sua morte, foram publicados os livros: “Diário de Bitita" (1982), “Meu estranho diário" (1996) e "Antologia pessoa" (1996). Apesar do seu empenho para manter-se no auge, Carolina acabou caindo no esquecimento, sendo silenciada e relegada ao insulamento.

\section{Carolina à margem do cânone}

Entre as diversas obras de Carolina, focamos nossa análise em "Quarto de despejo: diário de uma favelada", publicado em 1960, obra inovadora que, por meio do gênero textual diário, veio a romper com o discurso dominante consolidado no cânone. Adotamos o seguinte conceito de cânone, definido por José Luís Jobim: 
Nas artes em geral e na literatura, que nos interessa mais de perto, cânone significa um perene e exemplar conjunto de obras - os clássicos, as obras-primas dos grandes mestres -, um patrimônio da humanidade (e, hoje percebemos com mais clareza, esta "humanidade" é muito fechada e restrita) a ser preservado para futuras gerações, cujo valor é indisputável (JOBIM, 1992, p. 70).

Ao analisarmos a constituição do cânone na literatura, alguns questionamentos necessitam ser levantados: quem legitima o que pode e o que não pode ser considerado literatura no Brasil? E os escritores e suas obras? Por que uns, e não outros? Por que não Carolina Maria de Jesus? Por que Clarisse Lispector? Elas não foram contemporâneas? Ambas não escreveram sobre as profundas dores femininas sentidas no âmago do ser?

Em relação ao processo de composição dos cânones, verificamos não há lugar para a diversidade da sociedade, sendo privilegiados apenas os segmentos que constam no topo da pirâmide social, ou seja, a elite, geralmente rica e branca, desconsiderando principalmente os escritores negros, como se eles não tivessem capacidade de representar a literatura brasileira, nem possuíssem potencial de uma escrita de qualidade - resquícios da desvalorização construída ao longo da história brasileira com relação à pessoa negra.

Vale considerar que a estrutura canônica visava privilegiar segmentos específicos referentes a gênero, raça e classe social, ou melhor, homens, brancos e ricos, restando às minorias, isto é, aos negros e pobres, a exclusão, invisibilidade e o silenciamento no campo literário.

Jobim (1992) alerta para o fato de as culturas africana, asiática, indígena, muçulmana não terem representatividade nas obras canônicas da literatura, pois estas estão pautadas no ocidente, ignorando, assim, outras contribuições literárias. 
O conceito de cânone implica um princípio de seleção (e exclusão) e, assim, não pode se desvincular da questão do poder: obviamente, os que selecionam (e excluem) estão investidos da autoridade para fazê-lo e o farão de acordo com seus interesses (isto é: de classe, de sua cultura, etc.) (JOBIM, 1992, p. 70).

O procedimento de escolha do cânone sempre foi homogêneo, e essa homogeneidade conveniente garantiu a perpetuação da ideologia dominante, etnocêntrica e racista, silenciando outras vozes, outras escritas, outros autores. Ainda de acordo com Jobim (1992, p. 73), "O cânone está a serviço dos mais poderosos, estabelecendo hierarquias rígidas no todo social e funcionando com uma ferramenta de dominação." Logo, ele também cumpre o seu papel de manter e perpetuar a hegemonia nas sociedades.

A constituição do cânone está impregnada de intenções, cuja escrita em si não é tanto valorizada, mas sim os interesses por trás dessas escolhas. Podemos citar como exemplo o campo editorial, que dita o que deve ou não ser lido nos diversos espaços do Brasil, gerando, dessa forma, um pensamento hegemônico.

Ainda que não tenha encontrado espaço entre cânones, Carolina, que tinha muito a dizer por meio de suas "escrevivências" (EVARISTO, 2007), conseguiu atrair a atenção da sociedade, principalmente da classe dominante que, até então, ignorava e repugnava seus textos. Como deixou registrado em seu diário: "Os visinhos de alvenaria olha os favelados com repugnância. Percebo seus olhares de ódio porque eles não quer a favela aqui. Que a favela deturpou o bairro. Que tem nojo da pobreza. Esquecem que na morte todos ficam pobres..." (JESUS, 2004, p. 49).

Vale explicar que o conceito de "escrevivência" é de autoria da escritora Conceição Evaristo (2007), que o definiu como escrita pautada nas experiências que o autor impetra 
no transcorrer de sua vida. A trajetória inicial de vida de Conceição Evaristo muito se parece com a de Carolina, pois ela também nasceu em Minas Gerais, em 1946, e morou em uma favela da zona sul de Belo Horizonte. Órfã, muito cedo passou a trabalhar como empregada doméstica, porém, sua verve literária já se fazia presente desde os primeiros estudos. Conciliou trabalho e estudo durante toda a sua vida e, por isso, somente aos 25 anos, em 1971, pôde concluir o curso de formação de professores, antigo curso normal.

Conceição foi morar no Rio de Janeiro, quando aprovada em concurso público para o magistério. Formou-se em Letras na Universidade Federal do Rio de Janeiro (UFRJ) e fez doutorado em Literatura Brasileira na Universidade Federal Fluminense (UFF). Autora negra e consagrada, Conceição Evaristo tem diversos livros publicados, em especial o romance "Ponciá Vicêncio", de 2003, que aborda temas como a discriminação racial, de gênero e de classe. A autora foi e é protagonista de diversos estudos, dissertações e teses. Conquistou o Prêmio Jabuti, na categoria Contos e Crônicas, com "Olhos d'água".

\section{Carolina iletrada?}

A despeito do pouco estudo (sistematizado), Carolina era uma mulher que, independente da sua situação socioeconômica e intelectual extremamente letrada, utilizava sua escrita como ferramenta de denúncia, protesto e desabafo. Apesar disso, as críticas negativas sobre a escritora referem-se a ela como iletrada.

Segundo Magda Soares (2006, p. 56), "do ponto de vista social, o letramento é um fenômeno cultural relativo às atividades que envolvem a língua escrita", a ênfase recai nos "usos, funções e propósitos da língua escrita no contexto social”. Mesmo com algumas limitações ortográficas, a escritora apresentava bastante destreza e senso crítico, 
social e político, o que a permitia discorrer sobre múltiplas questões sociais. Sua escrita podia até contrariar algumas regras gramaticais, entretanto, semanticamente ultrapassava todas as expectativas por conta de sua clareza e objetividade e sua linguagem, ou escrevivência, constituída pelo ambiente de exclusão no qual estava inserida.

O termo "letramento" é atual e ainda suscita muitas dúvidas sobre o conceito, pois uns o associam apenas ao processo de alfabetização, enquanto outros o veem como metodologia. De acordo com a concepção de Soares (2004), o letramento pressupõe o uso da leitura e da escrita como instrumento social: e não é isso que Carolina faz com sua escrita? Então, por que chamá-la de iletrada? A escritora poderia até não possuir o domínio formal da escrita escolar (aquele planejado por critérios pedagógicos), mas possuía o letramento social (circunstância da vida) (SOARES, 2004).

O conceito de letramento, apesar de bastante complexo e múltiplo, abarca uma variada gama de informações, aptidões, competências, valores, modos, desempenhos, fato que dificulta uma acepção singular.

No entanto, de acordo com Magda Soares (2006), a alfabetização não garante a constituição de sujeitos letrados, pois o letramento é anterior à alfabetização, daí a importância de alfabetizar letrando ou letrar alfabetizando, em um processo constante que continua por toda a vida dos sujeitos. A leitura do mundo é anterior à leitura da palavra, conforme salienta Paulo Freire (1989, p. 9):

A leitura do mundo precede a leitura da palavra, daí que a posterior leitura desta não possa prescindir da continuidade da leitura daquele. Linguagem e realidade se prendem dinamicamente. A compreensão do texto a ser alcançada por sua leitura crítica implica a percepção das relações entre o texto e o contexto. 
Não obstante o pouco estudo formal, Carolina foi uma mulher que adquiriu o gosto pela leitura e pela escrita: lia bastante, escrevia bilhetes, diários, poesias, entre outras coisas. A escrita permitia sua reflexão sobre seu cotidiano, seus sentimentos, sua vida. Por meio da escrita, ela deixou seu legado e, escrevendo, mudou sua história. Mas a leitura também era um ideal para Carolina e, como ela mesma menciona: "Todos tem um ideal. O meu é gostar de ler." (JESUS, 2004, p. 25). Em seus escritos diários, de maneira simples e objetiva, Carolina abordava questões profundas sobre a existência e as oferecia aos seus leitores.

\section{Carolina e a literatura}

Representante de uma literatura viva, e contrariando o cenário no qual estava inserida, por meio de sua escrita, Carolina Maria de Jesus trouxe à tona temas polêmicos, como: miséria, discriminação social, preconceito, sexualidade, descaso dos políticos, entre outros. Sua narrativa se tornou instrumento de luta, denúncia e resistência.

“Quarto de despejo" é uma coletânea das lembranças de Carolina, que apresenta características das "escrevivências" de Conceição Evaristo, que certamente situa-se no rol das grandes obras, dos grandes escritores, pois expõe a enredamento de dramas sóciohistóricos, análises do cotidiano e experiências estéticas. O livro é resultado das suas odisseias, sua visão de mundo, seus relatos que vão de 15 de junho de 1955 a 1o de janeiro de 1960, como narrou:

15 de julho de 1955. Aniversário de minha filha Vera Eunice. Eu pretendia comprar um par de sapatos para ela. Mas o custo dos gêneros alimentícios nos impede a 
realização dos nossos desejos. Atualmente somos escravos do custo de vida. Eu achei um par de sapatos no lixo, lavei e remendei para ela calçar. 10 de janeiro de 1960. Levantei às 5 horas e fui carregar água. (JESUS, 2004, p. 36).

Através de sua narrativa reflexiva e denunciadora, aliada ao seu senso crítico, Carolina registrou a vida dos favelados e da cidade, por vezes de forma poética, em outras, dramática, revelando aos leitores outra face da sociedade. Em sua obra, podemos verificar o quão amplo era o seu conhecimento de mundo, pois faz referências a diversos contextos, situando-os historicamente. Através de seus singulares escritos, seus leitores têm a oportunidade de ampliar o conhecimento de mundo através da "voz corajosa" dessa mulher, de nome Carolina, que não teve medo de contar em seu diário tudo o que sentia, observava e pensava.

Conforme relatado em seu diário, Carolina almejava, ou melhor, sonhava, com a aquisição de um imóvel, uma casa de alvenaria para sua família. Queria morar na cidade, deixar a realidade da favela, que considerava o quarto de despejo da cidade, o lugar onde se depositava tudo o que não prestava, conforme narrou: "a favela é o quintal onde jogam os lixos" (JESUS, 2004, p. 43). Mas podemos ler seus sonhos e desejos, voltados para uma perspectiva de desejo de outra vida para si e seus filhos e de direitos e condições de igualdade aos demais moradores da cidade, bem como acesso à cidadania:

Sonhei que eu residia numa casa resilível, tinha banheiro, cozinha, copa e até quarto de criada. Eu ia festejar o aniversário de minha filha Vera Eunice. Sentei na mesa para comer. A toalha era alva ao lírio. Eu comia bife, pão com manteiga, batata frita e salada. Quando fui pegar outro bife despertei. Que realidade amarga! Eu não residia na cidade. Estava na favela. Na lama, às margens do Tietê (JESUS, 2004, p. 35). 
Com o êxito de sua obra, o sonho se tornou realidade e finalmente ela pôde deixar a favela. Carolina ascendeu via palavra e literatura, saindo da favela. Mas não adentrou de fato na "cidade", pois a favela não saiu dela, embora desejasse brilhar. Mudou-se para o bairro de Santana, em São Paulo, porém, como descreveu Fernandez (2008, p. 128): "Carolina não conseguiu viver em Santana. Brigou com todos os vizinhos, que a receberam mal." Dali, mudou-se para sítio em Parelheiros, onde começou a ser ignorada pelo mundo literário, até ser esquecida. Como explica Joel Rufino (2010, p. 56): “Passada a novidade, Carolina foi rejeitada por todos. Pela direita, por expor a miséria. Pela esquerda, porque não queria saber de luta social".

Aos 56 anos de sua publicação, "Quarto de despejo" continua bastante atual, pois vemos nas narrativas de Carolina que muitas denúncias feitas naquela época ainda são latentes no dia a dia de muitos brasileiros, mais precisamente nas classes subalternizadas, sendo inegável sua contribuição para reflexão e desinvisibilidade da opressão, sofrimento e luta das camadas populares e seu cotidiano. Entretanto, a escritora em vida não conseguiu se firmar no campo literário brasileiro. Foi um fenômeno aparentemente instantâneo que, apesar de suas ricas narrativas e da grande vendagem de seus livros, morreu pobre.

$\mathrm{Na}$ atualidade, Carolina Maria de Jesus tem sido alvo de variados estudos, provando que realmente não foi um fenômeno momentâneo, e sim uma mulher à frente do seu tempo, que foi invisibilizada e, por vezes, usada e desprezada. Não Ihe permitiram obter oportunidades suficientes para mantê-la no cenário literário que tanto almejava. $\mathrm{Na}$ verdade, mais uma vez, o sistema dominante prevaleceu e tentou calar sua voz, silenciando-a. Mas ela nunca parou de escrever. E nunca parou de dizer. Os seus escritos se tornaram a impressão da voz negra e feminina que se perpetuou através do tempo 
para que nunca se esqueçam de que a escritora Carolina Maria de Jesus foi uma mulher negra resistente e representante de uma literatura brasileira, dentro e fora do nosso país.

\section{Algumas considerações finais}

Diante da realidade constatada na história de Carolina Maria de Jesus, acreditamos que ainda há um grande desafio a ser superado, uma vez que a literatura brasileira foi e ainda é um campo de privilégios. Dar voz aos sujeitos historicamente excluídos e invisibilizados no decorrer da história é essencial para a promoção de uma literatura sob outra perspectiva.

Desinvisibilizar as falas de sujeitos subalternos e subalternizados ao longo da história e até hoje, a fim de que estas sejam escutadas, reverenciadas, lidas e refletidas, é um importante objetivo a ser alcançado. Daí a importância de uma educação antirracista e da formação de professores comprometidos com a diversidade cultural e com a eliminação dos mecanismos de exclusão simbólicos ou físicos.

A lei no 10.639/2003, ampliada pela lei no $11.645 / 2008$, foi uma importante conquista, resultado de lutas históricas do movimento negro. A referida lei é uma fundamental ferramenta para que parte do desafio mencionado acima seja alcançada, pois por meio dela, é possível a formação de sujeitos com novos olhares, preprados para a leitura sob novos ângulos e a aceitação de outras histórias (MÜLLER; COELHO, 2013).

A inclusão do artigo 26 da Lei de Diretrizes e Bases da Educação Nacional (LDB, no 9.394/96), que determina a obrigatoriedade da temática "História e Cultura AfroBrasileira no currículo", objetiva extinguir as desigualdades sociais que historicamente foram estabelecidas no período colonial e pós-colonial no país. 
$\S 1^{\circ} \mathrm{O}$ conteúdo programático a que se refere o caput deste artigo incluirá o estudo da História da África e dos Africanos, a luta dos negros no Brasil, a cultura negra brasileira e o negro na formação da sociedade nacional, resgatando a contribuição do povo negro nas áreas social, econômica e política pertinentes à História do Brasil (BRASIL, 2003, p. 1).

A obra e a história de Carolina Maria de Jesus é matéria-prima extraordinária tanto para auxiliar na aplicabilidade da lei no 10.639/2003, quanto para subsidiar os estudos no campo literário nacional e internacional. Carolina é uma expressiva representante da literatura afro-brasileira. Em suas obras artísticas estão materializadas sua criticidade, resistências e empoderamento para denunciar as desigualdades sociais e raciais.

Isso fica explícito quando em seu livro "Quarto de despejo" a autora denuncia que "o centro da cidade é a sala de visitas, a favela é o quarto onde se joga o indesejável, o entulho, tudo aquilo que se quer esconder" (JESUS, 2004, p. 43), como já destacamos. Para Joel Rufino (2009, p. 37), "sua escrita, no entanto, é sua forma de se recusar a ser 'despejo', a ser 'resto'.".

Maria Carolina de Jesus morreu no dia 13 de fevereiro de 1977, aos 62 anos de idade. Deixou sua marca impressa na história da literatura e também incomodou e desconstruiu muitos conceitos idealizados pelos cânones literários e pela elite brasileira. Ela foi de encontro ao modelo pré-estabelecido, rompeu com a linguagem apresentada como padrão e abordou temas plurais fora do previsível; desnorteou alguns leitores e encantou muitos outros por sua singularidade.

Ela ainda revelou em seus escritos muitas "marcas de oralidade", que entendemos como uma herança africana. Ao relatar as suas próprias histórias cotidianas em seus textos e diários, ela reverencia os Griós - indivíduos africanos que têm o compromisso de 
preservar e transmitir histórias e cultura. Na aparente simplicidade de sua literatura, quanta profundidade! Assim, nos resta a pergunta: por que não ler Carolina Maria de Jesus?

\section{Referências}

BRASIL. Ministério da Educação. Lei no 10.639 de 9 de janeiro de 2003. Altera a Lei nำ 9.394, de 20 de dezembro de 1996, que estabelece as diretrizes e bases da educação nacional, para incluir no currículo oficial da Rede de Ensino a obrigatoriedade da temática "História e Cultura Afro-Brasileira", e dá outras providências. Diário Oficial [da] República Federativa do Brasil, 10 jan. 2003.

Ministério da Educação. Diretrizes Curriculares Nacionais para a Educação das Relações Étnico-raciais e para o Ensino de História e Cultura Afro-Brasileira e Africana. Brasília, DF: MEC, 2004.

EVARISTO, Conceição. Da grafia-desenho de minha mãe um dos lugares de Nascimento de minha escrita. In: ALEXANDRE, Marcos Antônio (Org.). Representações performáticas brasileiras: teorias, práticas e suas interfaces. Belo Horizonte: Mazza Edições, 2007.

FREIRE, Paulo. A importância do ato de ler. São Paulo: Cortez, 1990.

FERNANDEZ Raffaella Andréa. Percursos de uma poética de resíduos na obra de Carolina Maria de Jesus. Itinerários, Araraquara, n. 27, p. 125-146, jul./dez. 2008.

JESUS, Carolina Maria de. Quarto de despejo: diário de uma favela. São Paulo: Ática, 2004. JOBIM, José Luis. (Org.). Palavras da crítica. Rio de Janeiro: Imago, 1992.

MEIHY, José Carlos. A fala da pobreza: Carolina Maria de Jesus. In: LIENHARD, Martín. Discursos sobre a pobreza: América Latina y países luso-africanos. Madrid/Frankfurt: Iberoamericana/Vervuert, 2006.

MÜLLER, Tânia Mara Pedroso; COELHO, Wilma de Nazaré Baia. Relações étnico-raciais e diversidade. Niterói: EdUFF, 2013. 
PESSOA, Fernando. Psicografia. 15 ed. Lisboa: Ática, 1995[1942].

RUFINO, Joel. Carolina de Jesus: uma escritora improvável. Rio de Janeiro: Garamond, 2010.

SKIDIMORE, Thomas. Preto no branco: raça e nacionalidade no pensamento brasileiro (1870-1930). São Paulo: Companhia das Letras, 2012.

SOARES, Magda. Letramento e alfabetização: as muitas facetas. Revista Brasileira de Educação. n. 25, jan/fev/mar/abr, 2004.

SPIVAK, Gayatri Chakravorty. Pode o subalterno falar? Belo Horizonte: Editora UFMG, 2010.

\footnotetext{
'Todas as citações da escritora neste texto foram transcritas ipsis litteris o original.
}

Recebido em 16 de março de 2018.

Aceito em 28 de maio de 2018. 